\title{
Word Processing of Children with Poor Reading Comprehension during an On-line Verbal Analogy Task
}

\author{
Byeong Jun Kimª, Mina Hwang ${ }^{\mathrm{b}}$, Kyung Soon Choi \\ ${ }^{a}$ Graduate School of Special Education, Dankook University, Yongin, Korea \\ ${ }^{b}$ Department of Special Education, Dankook University, Yongin, Korea \\ 'Department of Speech Therapy, Sangji Youngseo College, Wonju, Korea
}

Correspondence: Kyung Soon Choi, PhD Department of Speech Therapy, Sangii Youngseo College, 660 Woosan-dong, Wonju 220-713, Korea Tel: $+82-33-730-0807$

Fax: +82-33-730-0875

E-mail: rance21@hanmail.net

Received: June 20, 2013

Revised: July 30, 2013

Accepted: August 15, 2013
Objectives: Children with poor reading comprehension (poor comprehenders) show deficits in reading comprehension along with normal word decoding skills. Although their limited vocabulary knowledge has been reported, studies on the characteristics of their underlying semantic and phonological processing are limited. We investigated the word processing of Korean-speaking poor comprehenders using an online decision task during verbal analogy. Methods: The participants were 10 poor comprehenders and 12 typically developing children from grades 4th-6th. They performed the on-line decision tasks where verbal analogy questions of $A: B=C:(?)^{\prime}$ were presented on a computer screen. There were 3 types of target words: correct words, phonologically-related incorrect words, and semantically-related incorrect words. The children had to determine whether a target word was an appropriate answer for the preceding verbal analogy question. The reaction times and accuracies were measured. Results: For the correct words, the two groups did not significantly differ for both reaction times and accuracies. For the phonologically-related incorrect words, the poor comprehenders' reaction times were significantly slower than their peers, although the accuracies of the two groups were similar. For the semantically-related incorrect words, the poor comprehenders' performances were significantly less accurate and slower compared to their peers. Conclusion: These results indicated that poor comprehenders are inefficient in suppressing inappropriate but phonologically- or semantically-related words during word recognition. It is suggested that their deficits in reading comprehension may be partly associated with the inefficiency for inhibiting phonologically-similar words or contextually irrelevant meanings of words during reading comprehension.

Keywords: Poor comprehenders, Word processing, Word recognition, Vocabulary knowledge, Verbal analogy, Inhibitory deficits
읽기과정은 자동적으로 일어나는 복잡한 언어 및 인지능력의 산물이다. 읽기는 시각적으로 단어를 재인하고 단어의 뜻을 이해 하는 단어수준을 거쳐, 구문 및 문법능력에 알맞게 문장 및 글을 파악하고 추론하여 전체 내용을 이해하는 과정으로 나아간다. 이 러한 일련의 읽기과정에 어려움을 보이는 경우를 읽기장애라고 한 다. 언어이해 능력은 정상적이지만, 단어재인에 어려움을 겪는 경우
를 난독증(dyslexia)이라 하며, 정상적인 단어재인 능력이 있음에도 불구하고 읽기이해에서 어려움을 보이는 경우를 읽기이해부진 (reading comprehension deficit 혹은 poor comprehender)이라고 한다(Cain \& Oakhill, 2007; Catts, Kamhi, \& Adlof, 2012). 특히, 읽 기이해부진아동은 정상적인 음독능력을 보임을 감안할 때에 이들 의 부족한 읽기이해 능력은 음독과정이 아닌 부족한 언어이해 과 
정의 영향이라고 짐작할 수 있다.

어휘능력은 얼마나 많은 어휘를 알고 있는가의 양적 측면인 어휘 량(vocabulary size)과 단어 의미를 얼마나 깊이 있게 이해하는가의 질적 측면인 어휘지식(vocabulary knowledge)으로 구분할 수 있다 (Baker, Simmons, \& Kameenui, 1998). 효과적인 읽기이해를 위해 서는 어휘의 양적 측면과 더불어 질적으로 깊이 있는 어휘지식이 요구된다(Nation, Adams, Bowyer-Crane, \& Snowling, 1999; White, Graves, \& Slater, 1990). 어휘지식은 읽기이해 과정의 하위수준인 글에 제시된 문장 각각의 의미를 파악하는데 중요한 역할을 담당 할 뿐 아니라 상위수준에서 맥락에 적절한 글 내용 통합 및 추론을 도출하기 위한 중요한 기초 자원으로서 작용한다(Cain \& Oakhill, 2006). 이처럼 어휘지식은 읽기이해의 다양한 과정에서 작용하는 중요한 요인이다. 연구에 따르면, 읽기이해부진아동은 양적 측면인 어휘량뿐 아니라 질적인 어휘지식 역시 빈약하며(Baker et al., 1998; Catts, Adlof, \& Weismer, 2006; Kim \& Hwang, 2008; Nation, Clarke, Marshell, \& Durand, 2004), 어휘지식은 읽기이해부진아동을 판별 하는 중요요인으로도 보고되었다(Cain \& Oakhill, 2006; Jeong, 2009a; Nation \& Snowling, 1998).

단어유추는 'A:B=C:(?)'의 형식에서 제시된 $\mathrm{A}$ 와 $\mathrm{B}$ 의 관계를 파 악하여 (?)에 해당하는 단어를 추론하는 과제로서 어휘지식을 검사 하기 위해 사용하는 대표적 과제이다(Jeong, 2009a; Kim \& Hwang, 2008; Ko, 2006; Nippold, Erskine, \& Freed, 1998; Sternberg \& Nigro, 1980). 단어유추는 유추(analogy)의 논리적 사고를 바탕으로 (Masterson, Evans, \& Aloia, 1993), 제시된 단어들 간의 의미관계 를 파악하여, 이를 새로운 단어들 간의 관계에 적용하게 된다. 즉, “사과:과일=사자:(동물)”에서 목표 단어인 “(동물)”은 “사과-과일” 의 관계에서 추론(inference)된 의미관계를 바탕으로, "사자-(동 물)"의 관계에 적용(application)하는 내재적인 처리과정을 거친 결 과이다. 앞서 언급한 바와 같이 읽기이해부진아동이 어휘지식에서 어려움을 보인다는 사실에 근거하여 볼 때, 어휘 지식의 내재적인 처리과정에서도 일반아동과 다른 양상을 보일 가능성이 높다.

어휘수준의 내재적인 처리과정은 단어재인, 어휘접속, 어휘해석 으로 이루어진다(Tabossi \& Zardon, 1993; Zoh et al., 2003). 단어재 인은 단어의 형태 및 음운과 같은 구조적인 정보들을 대응시켜 단 어를 확인하는 과정으로, 초기단계에서 이루어진다. 어휘접속에서 는 확인된 단어와 연결된 의미 연결경로(semantic network) 및 음운 연결경로(phonological network)를 통해 어휘집(mental lexicon)에 있는 관련된 의미 및 음운 정보가 활성화되고, 최종적으로 맥락에 따라 올바른 의미로 단어가 해석되어가는 과정으로 나아간다. 이 러한 일련의 과정에서 목표된 단어와 의미 또는 음운적으로 유사
한 단어들이 함께 활성화되기도 하는데, 읽기이해부진아동의 경우 그들의 빈약한 어휘지식으로 인하여 또래 일반아동과 비교하여 관 련 단어들간의 활성화 효과가 낮았다(Choi \& Hwang, 2010). 반면 성공적으로 단어를 재인하고 해석하기 위하여서는 활성화된 다양 한 정보들 중에서 부적절한 정보를 빠르게 억제하는 것이 필수적 이다. 결국, 내재적인 처리과정은 외부에서 입력된 정보를 바탕으로 활성화된 다양한 의미 및 음운 정보들 중에서 가장 관련성이 높은 의미를 찾아가는 과정이며, 성공적인 읽기이해를 위해서는 내재적 처리과정에 있어서 적절한 정보의 강력한 활성화뿐만 아니라 부적 절한 정보의 빠른 억제가 효율적으로 이루어져야 한다(Gernsbacher \& Faust, 1991). 읽기이해 능력이 미숙할수록 활성화된 다양한 정보들 중에서 부적절한 정보를 효율적으로 억제하는데 어려움을 보인다(Gernsbacher \& Faust, 1991; Ko, Choi, \& Hwang, 2010). Ko 등 (2010)은 읽기이해부진아동이 문장 안에 제시된 다의어를 해석 함에 있어, 다의어의 여러 뜻 중에서 맥락에 적절한 뜻만 활성화하 고 나머지는 억제하는 능력이 일반아동에 비해 저조함을 보고하였 다. 본 연구는 어휘수준의 내재적 처리과정에서 읽기이해부진아동 의 부적절한 정보 억제 능력이 일반아동과 비교하여 어떠한 양상 을 보이는지 알아보기 위하여 단어 유추를 활용한 온라인 판단과 제를 실시하였다.

본 연구에서는 단어유추를 온라인으로 제공하여 'A:B=C:(?)'의 형식에서 (?)에 해당하는 목표단어를 제시하였다. 구체적으로 읽기 이해부진아동이 정답에 해당하는 목표단어가 정답임을 빠르고 정 확하게 판단하는 능력뿐 아니라, 음운적 또는 의미적으로 관련되 지만 오답인 목표단어를 부적절하다고 판단하는 능력에 있어서 일 반아동들과 차이가 있는지 조사하였다.

\section{연구 방법}

\section{연구 대상}

연구 대상은 서울 및 경기지역 초등학교 재학 중인 $4,5,6$ 학년 읽 기이해부진아동 10 명, 일반아동 12 명으로 총 22 명이었다. 읽기이해 부진아동의 선정기준은 다음과 같다. 1) 부모 및 교사에 의해 읽기 이해에 어려움이 있는 것으로 보고된 아동들 중에서, 2) 저성취 모 델(low achievement model)에 근거하여(Fletcher et al., 2002), 기초 학력검사(Park, Kim, Song, Jeong, \& Jeong, 2008)의 짧은 글 이해 소검사에서 백분위 25 이하에 속하고, 3) 음독 소검사에서는 백분 위 25 이상에 속하며, 4) Korean Wechsler Intelligence Scale for Children III (K-WISC III; Kwak, Park, \& Kim, 2001)의 동작성 지 능이 85 이상에 속하는 아동이었다. 선정된 읽기이해부진아동은 
남자가3명, 여자가 7명이었다.

일반아동의 선정기준은 다음과 같다. 1) 부모 및 교사에 의해 읽 기이해에 어려움이 없는 것으로 보고된 아동들 중에서, 2) 기초학 력검사(Park et al., 2008)의 음독 소검사와 짧은 글 이해 소검사 모 두에서 백분위 25 이상에 속하며, 3) K-WISC III (Kwak et al., 2001) 의 동작성 지능이 85 이상에 속하는 아동이었다. 선정된 일반아동 은 남자가 3 명, 여자가 9 명이었다.

선정된 연구대상 아동들은 감각적, 신경학적 문제가 없으며, 정서 및 행동상의 문제가 없음을 부모 또는 교사에게서 확인하였다. 두 집단 아동들은 동작성 지능 $\left(t_{(20)}=-1.017, p>\right.$.05)과 음독능력 $\left(t_{(20)}=\right.$ $-1.218, p>.05)$ 에서는 두 집단간의 차이가 통계적으로 유의미하지 않았으나, 짧은 글 이해에서는 집단간 차이가 통계적으로 유의미하 였다 $\left(t_{(20)}=-5.172, p<.001\right)$. 연구대상의 정보는 Table 1 와 같다.

\section{도구}

실험도구는 단어유추 판단과제로서 교육 및 연습시행 20 문항, 본 시행 72 문항으로 구성하였다. 72 회 본 시행 항목 중 36 문항은 음 운관련 오답 조건 18 문항, 의미관련 오답 조건 18 문항으로 "아니 오” 반응을 유도하는 문항으로 구성하였고, 나머지 반인 36문항은 "예" 반응을 이끌기 위한 정답 조건으로 구성하였다. 단어유추 문 항은 Ko (2006), Jeong (2009a)의 연구 과제를 수정 보완하여 사용 하였다. 72 개 목표단어 중 “아니오” 판단을 위한 목표 단어는 음운 관련 오답 조건 단어 18 개, 의미관련 오답 조건 단어 18 개로 선정하 였으며, 이에 대응되는 “예” 판단을 위한 정답 조건 단어 36 개를 선 정하였다. 본 연구에 사용된 모든 단어들은 '등급별 국어교육용 어 휘(Kim, 2003)'의 1-3등급 내에 있는 단어들이었다.

구체적으로 음운관련 오답 조건과 의미관련 오답 조건의 목표단 어는 다음과 같은 기준으로 구성되었다. 음운관련 오답 조건의 목 표단어는 유추된 정답과 음운적 유사성이 높은 오답으로, 음운적 유사성을 높이기 위하여 정답과 2음절 초성까지 일치하는 단어를 선정하였다(예: 문항 “비:날씨=가을:(?)” - 정답 “계절” - 음운관련

Table 1. Group characteristics

\begin{tabular}{|c|c|c|c|}
\hline \multirow[t]{2}{*}{ Characteristic } & $\begin{array}{c}\text { Poor compre- } \\
\text { henders }(n=10)\end{array}$ & $\begin{array}{c}\text { Good compre- } \\
\text { henders }(n=12)\end{array}$ & \multirow[t]{2}{*}{$t$} \\
\hline & Mean (SD) & Mean (SD) & \\
\hline Grade & $4.90(0.74)$ & $5.17(0.94)$ & -0.730 \\
\hline K-WISC III (standard scores) & $104.80(14.14)$ & $110.58(12.54)$ & -1.017 \\
\hline Decoding (raw scores) & $23.50(0.71)$ & $23.83(0.58)$ & -1.218 \\
\hline Text comprehension (raw scores) & $9.90(3.04)$ & $19.50(5.16)$ & $-5.172^{*}$ \\
\hline
\end{tabular}

K-WISC III = Korean Wechsler Intelligence Scale for Children III. ${ }^{*} p<.001$
오답 조건 목표단어 “계집”). 의미관련 오답 조건의 목표단어는 'A:B=C:(?)'의 유추형식에서 $\mathrm{C}$ 와 의미적으로 관련된 단어를 선정 하였다(예: 문항 “방석:엉덩이=베개:(?)" - 정답 “머리” - 의미관련 오답 조건의 목표단어 “이불”). 정답 조건의 목표단어는 유추 결과 로 선정된 정답 단어였다(예: 문항 “하나:둘=다섯:(?)” - 정답 및 목 표단어 “여섯”). 모든 목표단어는 2음절로 구성하였다.

최종 연구문항을 선정하기 위하여 두 차례의 예비실험을 실시하 였다. 먼저, 일반인 9명(성인 및 초등학교 4학년)을 대상으로 지필형 식의 단어유추 판단과제 150 문항을 실시하여 정반응률이 $50 \%$ 이 상인 문항을 92 개를 선정하였다. 이어서 앞서 선정된 92 문항을 온 라인 판단과제로 제작하여, 초등학교 고학년 일반아동 7명에게 실 시하였다. 아동의 수행 결과 오반응률이 $50 \%$ 이상이거나 반응시간 이 2초 이상인 문항을 제외하여 본 시행 문항을 선정하였다. 최종 적으로 “아니오” 반응을 위한 음운관련 오답 조건 18문항, 의미관 련 오답 조건 18 문항을 선정하였고, 이에 대비하여 “예” 반응을 위 한 정답 조건 36 문항을 선정하여 본 시행 문항을 구성하였다. 또한 연구대상에게 과제 수행 방법을 학습시키기 위한 교육 및 연습문 항 20 개를 별도로 제작하였다. 교육 및 연습시행은 음운관련 조건 5 회, 의미관련 조건 5 회, 정답 조건 10 회로 구성되었다.

\section{연구 절차}

실험은 조용한 방에서 개별적으로 진행되었다. 자극의 제시와 측정은 노트북(SAMSUNG Sens R410)을 이용한 E-PRIME 2.0 (2007)으로 이루어졌다. 본 시행 문항은 무선적으로 제시되었으며, 아동은 36 회의 본 시행을 수행한 후 2 분 이내의 짧은 휴식을 가지 고, 나머지 본 시행을 수행하였다. 모든 문항은 13 인치 노트북 모니 터의 흰 바탕에 18 폰트의 검정색 명조체로 제시되었다. 검사자는 아동에게 목표단어를 보고 정답이면 마우스 왼쪽의 “예" 버튼을, 오답이면 마우스 오른쪽의 “아니오” 버튼을 눌러 반응하도록 하였 다. 연구자는 아동에게 모니터를 통해 다음과 같은 실험 지시문을 보여주었다. “화면에 ‘ $\mathrm{A}: \mathrm{B}=\mathrm{C}:(?)$ ' 형식의 문항이 나타날 거예요. 그 럼 $\bigcirc \bigcirc$ 아동은 화면을 잘 보고 (?)에 해당하는 답이 생각나자마자 SPACE BAR을 누르세요. 그럼 문항 밑줄에 (?)에 해당하는 어떤 단 어가 나타나요. $\bigcirc$ 아동이 이 단어를 보자마자 정답이라고 생각 되면 “예” 버튼을, 오답이라고 생각되면 "아니오” 버튼을 누르세 요. 단어가 나오자마자 정확하게 판단하고 빠르게 누르는 것이 중 요해요.” 실험자는 모든 아동들에게 20 회의 교육 및 연습시행을 실 시하여 과제수행 방법을 습득한 지 확인한 후 본 시행을 실시하였 다. 만일 아동이 이해하지 못한 경우 1 회에 한하여 연습시행을 반 복하여 수행할 수 있었다. 모든 아동이 수행방법을 충분히 숙지했 
음을 확인한 후 본 시행을 실시하였다.

단어유추 판단과제 1 회 수행 절차는 다음과 같았다. 먼저 화면 중앙에 응시점(+)이 $250 \mathrm{~ms}$ 동안 나타났다가 자동적으로 사라지 면, 단어유추의 'A:B=C:(?) 형태의 문항이 제시되었다. 아동이 (?) 에 해당하는 목표단어가 연상되자마자 SPACE BAR를 누르면 해 당 문항의 목표단어가 단어유추 문항 밑줄에 나타났다. 아동은 목 표단어를 보고 정/오답을 판단하여 마우스 왼쪽의 "예" 버튼 또는 마우스 오른쪽의 “아니오” 버튼을 눌맀다. 아동이 버튼을 누르자 마자 화면이 사라지고 $50 \mathrm{~ms}$ 동안 빈 화면이 나타난 다음에 다음 시 행의 응시점(+)이 나타났다. 아동의 판단 반응시간은 아동이 목표 단어를 보기 위하여 SPACE BAR을 누른 시점부터 정/오답을 판단 하여 마우스 버튼을 누르는 순간까지의 시간이며, 이는 컴퓨터에 자동으로 기록되었다.

아동의 물리적 단순반응시간이 본 실험과제에 미치는 영향을 배 제하기 위하여 따로 단순반응과제를 실시하여 반응시간을 측정하 였다. 단순반응과제는 흰색 모니터의 중앙에 30 폰트로 제시되는 응시점(+)을 보는 순간 SPACE BAR를 누르는 것으로 총 30 회를 별 도로 시행하였다.

\section{자료 분석}

본 연구에서 수집된 데이터는 SPSS ver. 12.0 (SPSS Inc., Chicago, $\mathrm{IL}, \mathrm{USA})$ 을 사용하여 집단(2) $\times$ 목표단어 조건(3)의 이원분산분석 (two-way ANOVA)으로 분석하였고, 목표단어 조건은 반복측정 (repeated measure)되었다. 분석결과에서 나온 상호작용효과가 어 느 조건에서의 차이인지를 알아보기 위해, 조건 별로 집단 간의 차 이를 t검정으로 분석하였다.

\section{연구 결과}

\section{단어유추 판단과제의 목표단어 판단의 정확도}

읽기이해부진아동과 일반아동의 단어유추 판단과제에서 목표 단어 판단의 정확도에 대한 기술통계는 Table 2와같다.

읽기이해부진아동과 일반아동이 목표단어 조건에 따른 정확도 에 차이를 보이는지 알아보기 위하여 이원분산분석을 실시하였다. 그 결과 집단 $\left(F_{(1,20)}=5.768, p<.05\right)$ 과 목표단어 조건 $\left(F_{(2,40)}=18.521\right.$, $p<.001)$ 의 주효과가 유의미하였고, 집단과 목표단어 조건간의 상 호작용 효과도 유의미하였다 $\left(F_{(2,40)}=6.697, p<.01\right)$. 이원분산분석 결과에서 나온 집단과 목표단어 조건 간의 상호작용 효과가 어느 조건에서의 차이로 인한 것인지 알아보기 위하여, 목표단어 조건에 따른 $t$ 검정을 실시하였다. 그 결과 음운관련 조건과 정답 조건의 정 확도에서는 두 집단의 차이가 통계적으로 유의미하지 않았으나, 의 미관련 조건에서 읽기이해부진아동의 정확도가 일반아동에 비하 여 유의미하게 낮았다 $\left(t_{(20)}=-3.369, p<.01\right)$. 다시 말하면, 읽기이해 부진아동들은 단어유추 과제를 수행할 때 의미적으로 관련된 오답 에 대해서 “아니오”라고 판단하는 정확도가 일반아동보다 낮았다.

\section{단어유추 판단과제의 목표단어 판단의 반응시간}

읽기이해부진아동과 일반아동의 단어유추 판단과제에서 목표 단어 판단의 반응시간에 대한 기술통계는 Table 3과 같다.

읽기이해부진아동과 일반아동이 목표단어 조건에 따른 반응시 간에 차이를 보이는지 알아보기 위하여 이원분산분석을 실시하였 다. 단순반응과제에서 읽기이해부진아동은 평균반응시간 263.60 $\mathrm{ms}$ 표준편차 $29.29 \mathrm{~ms}$ 이며, 일반아동의 평균반응시간 $250.42 \mathrm{~ms}$ 표준편차 $21.48 \mathrm{~ms}$ 으로 집단 간의 차이가 없었으므로 $\left(t_{(20)}=1.219\right.$,

Table 2. Accuracies of performance during the on-line verbal analogy task (\%)

\begin{tabular}{lccc}
\hline & \multicolumn{2}{c}{ "NO" reaction condition } & "YES" reaction condition \\
\cline { 2 - 3 } & Phonologically-related & Semantically-related & \\
\hline Poor comprehenders $(n=10)$ & $87.22(17.77)$ & $60.00(22.19)$ & $90.83(10.56)$ \\
Good comprehenders $(n=12)$ & $89.81(7.43)$ & $84.26(10.54)$ & $92.82(5.86)$ \\
\hline
\end{tabular}

Values are presented as mean (SD).

Table 3. Reaction times of performance during the on-line verbal analogy task (ms)

\begin{tabular}{lcc}
\hline & \multicolumn{2}{c}{ "NO" reaction condition } \\
\cline { 2 - 3 } & Phonologically-related & Semantically-related \\
\hline Poor comprehenders $(n=10)$ & $1,189.90(289.08)$ & $1,304.98(243.60)$ \\
Good comprehenders $(n=12)$ & $807.33(148.78)$ & $978.87(233.82)$ \\
\hline
\end{tabular}

Values are presented as mean (SD). 
$p>.05)$ 공변량은 실시하지 않았다. 이원분산분석 결과, 집단 $\left(F_{(1,20)}=\right.$ $14.233, p<.01)$ 과 목표단어 조건 $\left(F_{(2,40)}=40.852, p<.001\right)$ 의 주효과 가 유의미하였고, 집단과 목표단어 조건간의 상호작용 효과도 유의 미하였다 $\left(F_{(2,40)}=6.064, p<.01\right)$. 이원분산분석 결과에서 나온 집단 과 목표단어 조건 간의 상호작용 효과가 어느 조건에서의 차이로 인한 것인지 알아보기 위하여, 목표단어 조건에 따른 $t$ 검정을 실시 하였다. 그 결과, 정답 조건의 반응시간에서는 두 집단의 차이가 통 계적으로 유의미하지 않았으나 음운관련 조건 $\left(t_{(20)}=4.005, p<.01\right)$ 과 의미관련 조건 $\left(t_{(20)}=3.197, p<.01\right)$ 에서는 읽기이해부진아동이 일반아동에 비하여 유의미하게 반응시간이 느렸다.

\section{논의 및 결론}

본 연구는 읽기이해부진아동의 어휘지식 접근의 내재적 처리과 정을 살펴보고자 단어유추 온라인 판단과제를 실시하였다. 이를 위하여 초등학교 고학년 읽기이해부진아동과 일반아동에게 온라 인으로 'A:B=C:(?)' 형식의 단어유추를 실시하고 (?)에 목표단어를 제시하였다. 아동은 (?)에 해당하는 목표단어가 정답인 조건, 음운 관련 오답 조건 및 의미관련 오답 조건에서 목표단어를 보고 예/아 니오 판단을 수행하였다. 목표단어가 정답인 경우, 읽기이해부진아 동은 수행 정확도와 반응시간에서 일반아동과 유의미한 차이를 보이지 않았으나, 음운관련 오답 조건에서는 읽기부진아동의 반응 시간이 일반아동보다 유의미하게 느렸고, 의미관련 오답 조건에서 는 정확도와 반응시간 모두에서 읽기이해부진아동이 일반아동에 비하여 유의미하게 저조하였다.

읽기이해부진아동은 실시간 단어유추 과제에서 음운적으로 관 련된 유사한 오답에 대해 부적절하다는 판단은 일반아동만큼 할 수 있으나, 판단을 내리기까지 유의미하게 더 오랜 시간이 걸렸다. 이는 정상적인 단어재인 능력을 가진다고 알려진(Cain, Oakhill, \& Bryant, 2000; Nation et al., 2004) 읽기이해부진아동이 어휘처리에 있어서 음운적으로 관련된 부적절한 정보를 억제할 수는 있지만 억제의 처리과정은 느리고 비효율적으로 이루어지고 있다고 해석 할 수 있다. 이러한 결과는 한글을 읽는 읽기이해부진아동이 비효 율적인 단어재인 양상을 보인다는 선행연구(Hwang \& Choi, 2011) 결과와 맥을 같이 한다. 최근 Hwang과 Choi (2011)는 읽기이해부 진아동을 대상으로 단어길이에 따른 단어재인 과정을 일반아동과 비교하였는데, 읽기이해부진아동은 단어길이가 길어질수록 어휘 판단의 속도가 느리고 오반응수가 유의미하게 높았다는 결과를 보 고하였다. 이 결과에 대하여 연구자들은 적어도 한글을 읽는 읽기 이해부진아동은 정확도로 측정되는 표준화된 음독과제의 수행 결
과는 정상범주에 속하나, 단어재인에서 비효율적인 처리가 이루어 지는 것으로 보인다고 설명하였다. 또한 읽기이해부진아동의 정상 적인 단어재인 능력에 대하여 한국어와 같이 자소-음소 대응이 투 명한 언어의 경우, 음독능력의 측정은 단순한 정확도보다는 처리 속도를 측정하는 것이 보다 효율적이라고 설명하기도 했다(de Jong \& van der Leij, 2002). 본 연구에서 읽기이해부진아동이 음운관련 오답 판단에 있어 일반아동과 유사한 정확도를 보이나 반응속도에 서 유의미한 차이를 보인 결과에 비추어 볼 때, 적어도 한국어를 사 용하는 읽기이해부진아동은 단어재인에 있어 비효율적인 처리과 정을 가질 수 있을 것이라 예상할 수 있다. 이러한 결과는 지금까지 정확도 중심으로 측정한 음독과제의 수행결과를 기반으로 읽기이 해부진아동이 정상적인 음독능력을 지닌다는 주장에 대하여, 최 소한 자소-음소 대응이 투명한 언어권에 있는 읽기이해부진아동 에 대하여서는 좀 더 구체적인 연구가 보완되어야 한다는 필요성을 제기할 수 있을 것이다.

읽기이해부진아동의 비효율적인 처리결함은 의미관련 오답 조 건에서 더욱 두드러지게 나타났다. 읽기이해부진아동은 의미관련 오답 조건에서 일반아동과 비교하여 유의미하게 저조한 정확도를 보였을 뿐만 아니라 반응시간도 유의미하게 느렸다. 읽기이해부진 아동의 저조한 수행 정확도는 이들이 보이는 취약한 어휘지식의 영 향이라고 생각할 수 있다(Baker et al., 1998; Catts, Adlof, \& Weismer, 2006; Kim \& Hwang, 2008; Nation et al., 2004). 뿐만 아니라 느린 처리 속도는 읽기이해부진아동이 단어유추 맥락 속에서 부적 절한 의미정보들을 보다 신속하고 강하게 억제하는데도 취약함을 보이는 것으로 해석할 수 있다(Cain, 2006; Ko et al., 2010; Pimpertom \& Nation, 2010). 다시 말하자면, 읽기이해부진아동은 취약한 어휘지식을 가질 뿐만 아니라 의미적으로 관련된 부적절한 정보를 억제함에 있어서도 비효율적이었다. 읽기이해부진아동의 취약한 어휘지식과 비효율적인 부적절한 의미정보 억제 능력은 문장에서 다양한 단어와 관련된 맥락을 효율적으로 처리해야 하는 읽기이해 를 방해하는 주된 요소로 작용하고 있는 것이다. 본 연구 결과, 읽기 이해부진아동은 단어들 간의 의미관계를 파악하고 적용하기까지 더 오랜 시간이 걸리며, 단어들 간의 관계가 적절하게 연결되었을지 라도 밀접하게 연결되어 있지 않아 단어의미처리가 비효율적일 것 이라 예상할 수 있다.

흥미로운 사실은 정답 조건에서 읽기이해부진아동의 정확도와 반응시간이 일반아동과 비교하여 유의미한 차이를 보이지 않았다 는 점이다. 이는 읽기이해부진아동이 일반아동과 비교하여 저조한 단어유추 능력을 보인다는 결과(Jeong, 2009b; Kim \& Hwang, 2008) 와는 다소 상이하다고 여겨진다. 그러나 이러한 수행 차이는 검사 
도구의 수행 방식 차이와 관련 지어 생각할 수 있다. 기존의 단어유 추 과제는 제시된 문항을 보고 정답 단어를 생성하여 지필하는 방 식인 반면, 본 연구는 정답 단어를 생성해내는 과정이 아닌 단어유 추를 통하여 제시된 목표단어의 정답 여부를 판단하는 과제였다. 읽기이해부진아동은 목표단어를 생성하여 기입하는 과제보다 제 시된 목표단어의 정답 여부를 판단하는 과제가 비교적 쉬웠을 것 이다. 정답 조건에서 읽기이해부진아동이 일반아동과 유사한 정확 도 및 반응시간을 보인 것은 읽기이해부진아동이 단어유추를 통 해 스스로 정답 단어를 생성함에는 어려움을 보이지만, 적어도 제 시된 정답의 목표단어를 보고 유추관계에 적절한 정답이라고 판단 함에는 제한적이지만 보다 수월했을 것으로 예상할 수 있다.

본 연구는 단어유추 온라인 판단 과제를 활용하여 읽기이해부 진아동의 내재적 어휘처리의 효율적인 억제 및 활성화 과정에 대하 여 음운과 의미 차원으로 알아보았다. 본 연구에서 나타난 읽기이 해부진아동의 비효율적인 내재적 단어처리 양상은 영어권 국가를 중심으로 사용 중인 읽기장애 분류 중 읽기이해부진아동의 조건 을 한국어와 같은 언어에 적용하여 해석하기에는 한계가 있을 수 있으며, 읽기이해부진아동의 선정기준에 대한 고찰이 보완되어야 한다는 것을 보여준다. 향후 어휘수준 이상에서의 내재적인 처리 양상을 알아본다면 읽기이해부진아동의 취약한 읽기이해능력에 대한 추가적인 정보를 얻을 수 있을 것이다.

\section{REFERENCES}

Baker, S. K., Simmons, D. C., \& Kameenui, E. J. (1998). Vocabulary acquisition: research bases. In D. C. Simmons, \& E. J. Kameenui (Eds.), What reading research tells us about children with diverse learning needs: bases and basics (pp. 183-217). Mahwah, NJ: Erlbaum.

Cain, K. (2006). Individual differences in children's memory and reading comprehension: an investigation of semantic and inhibitory deficits. Memory, 14, 553-569.

Cain, K., \& Oakhill, J. (2006). Profiles of children with specific reading comprehension difficulties. British Journal of Educational Psychology, 76, 683696.

Cain, K., \& Oakhill, J. (2007). Reading comprehension difficulties: correlates, causes, and consequences. In K. Cain \& J. Oakhill (Eds.), Children's comprehension problems in oral and written language: a cognitive perspective (pp. 41-75). New York, NY: Guilford Press.

Cain, K., Oakhill, J., \& Bryant, P. (2000). Phonological skills and comprehension failure: a test of the phonological processing deficit hypothesis. Read- ing and Writing, 13, 31-56.

Catts, H. W., Adlof, S. M., \& Weismer, S. E. (2006). Language deficits in poor comprehenders: a case for simple view of reading. Journal of Speech, Language, and Hearing Research, 49, 278-293.

Catts, H. W., Kamhi, A. G., \& Adlof, S. M. (2012). Defining and classifying reading disabilities. In H. W. Catts \& A. G. Kamhi (Eds.), Language and reading disabilities, 3rd ed. (pp. 45-76). Boston, MA: Allyn \& Bacon.

Choi, K. S., \& Hwang, M. (2010). Semantic processing in children with poor reading comprehension: semantic priming effect during word reading. Korean Journal of Communication Disorders, 15, 168-176.

de Jong, P. F., \& van der Leij, A. (2002). Effects of phonological abilities and linguistic comprehension on the development of reading. Scientific Studies of Reading, 6, 51-77.

Fletcher, J. M., Lyonm, G. R., Barnes, M., Stuebing, K. K., Francis, D. J., Olson, R. K., ... Shaywitz, B. A. (2002). Classification of learning disabilities: an evidence-based evaluation. In R. Bradley, L. Danielson, \& D. P. Hallahan (Eds.), Identification of learning disabilities: research to practice (pp. 185250). Mahwah, NJ: Erlbaum.

Gernsbacher, M. A., \& Faust, M. E. (1991). The mechanism of suppression: a component of general comprehension skill. Journal of Experimental Psychology, 17, 245-262.

Hwang, M., \& Choi, K. S. (2011). Word length effect in the lexical decisions of poor comprhenders. Korean Journal of Communication Disorders, 16, 570-581.

Jeong, M. (2009a). The predictors of poor comprehenders' reading comprehension in 3 to 6 grades (Doctoral dissertation). Dankook University, Yongin, Korea.

Jeong, M. (2009b). Verbal analogical reasoning skills in poor comprehenders. Korean Journal of Communication Disorders, 14, 275-287.

Kim, A. H., \& Hwang, M. (2008). Prediction of reading skills in upper elementary students. Korean Journal of Communication Disorders, 13, 1-25.

Kim, K. H. (2003). Grade level vocabulary list. Seoul, Korea: Pakijung. Ko, S., Choi, K. S., \& Hwang, M. (2010). Comprehension of ambiguous words in children with poor reading comprehension. Korean Journal of Communication Disorders, 15, 348-356.

Ko, Y. M. (2006). Verbal analogical reasoning skills in children with specific language impairment (Master's thesis). Dankook University, Yongin, Korea.

Kwak, K. C., Park, H. W., \& Kim, C. T. (2001). Korean Wechsler intelligence scale for children-III (K-WISC-III). Seoul: Seoul Special Education Publishing Co. 
Masterson, J. J., Evans, L. H., \& Aloia, M. (1993). Verbal analogical reasoning in children with language learning disabilities. Journal of Speech and Hearing Research, 36, 76-82.

Nation, K., \& Snowling, M. J. (1998). Semantic processing and the development of word-recognition skills: evidence from children with reading comprehension difficulties. Journal of Memory and Language, 39, 85-101.

Nation, K., Adams, J. W., Bowyer-Crane, C. A., \& Snowling, M. J. (1999). Working memory deficits in poor comprehenders reflect underlying language impairment. Journal of Experimental Child Psychology, 73, 139-158.

Nation, K., Clarke, P., Marshell, C. M., \& Durand, M. (2004). Hidden language impairments in children: parallels between poor reading comprehension and specific language impairment? Journal of Speech, Language, and Hearing Research, 47, 199-211.

Nippold, M. A., Erskine, B. J., \& Freed, D. B. (1998). Proportional and functional analogical reasoning in normal and language-impaired children. Journal of Speech and Hearing Disorders, 53, 440-448.
Park, K. S., Kim, G. O., Song, Y. J., Jeong, D. Y., \& Jeong, I. S. (2008). KISE Basic Academic Achievement Test. Asan: Korea National Institute for Special Education.

Pimpertom, H., \& Nation, K. (2010). Suppressing irrelevant information from working memory: evidence for domain-specific deficits in poor comprehenders. Journal of Memory and Language, 62, 380-391.

Sternberg, R. J., \& Nigro, G. (1980). Developmental patterns in the solution of verbal analogies. Child Development, 51, 27-38.

Tabossi, P., \& Zardon, F. (1993). Processing ambiguous words in context. Journal of Memory and Language, 32, 359-372.

White, T. G., Graves, M. F., \& Slater, W. H. (1990). Growth of reading vocabulary in diverse elementary schools: decoding and word meaning. Journal of Educational Psychology, 82, 281-290.

Zoh, M. H., Lee, J. M., Kim, J. O., Shin, H. J., Lee, K. O., Doh, K. S., ... Jung, H. S. (2003). Psychology of language. Seoul: Hakjisa. 


\section{국문초록}

\section{읽기이해부진아동의 단어유추를 통한 단어처리 특성}

\section{김병준 ${ }^{1} \cdot$ 황민아 $^{2} \cdot$ 최경순 ${ }^{3}$}

1단국대학교 특수교육대학원, ${ }^{2}$ 단국대학교 특수교육과, ${ }^{3}$ 상지영서대학교 언어재활과

배경 및 목적: 읽기이해부진아동은 정상적인 단어재인능력을 가짐에도 불구하고 읽기이해에 어려움을 보이는 아동을 지칭한다. 읽기 이해부진아동의 부족한 어휘지식은 이미 밝혀졌으나, 어휘수준의 내재적인 음운 및 의미 처리특성에 대한 연구는 드문 실정이다. 본 연 구에서는 단어유추 온라인 판단과제를 이용하여 읽기이해부진아동의 내재적 단어처리 특성을 알아보았다. 방법: 연구대상은 초등학 교 4-6학년의 읽기이해부진아동 10 명과 일반아동 12 명이었다. 아동들에게 온라인으로 단어유추(A:B=C:(?))를 실시하고 (?)에 해당하 는 목표단어를 음운관련 오답, 의미관련 오답 및 정답의 3 가지 조건으로 제시하여 적절성 판단하도록 하였고, 수행에 대한 정확도와 정 확도의 반응시간을 측정하였다. 결과: 읽기이해부진아동은 목표단어가 정답 조건에서는 정확도와 반응시간에서 일반아동과 유사한 수행을 보였다. 반면, 음운관련 오답 조건에서 읽기이해부진아동은 일반아동과 유사한 수준의 정확도를 보였으나, 반응시간은 유의미 하게 느렸다. 의미관련 오답 조건에서 읽기이해부진아동은 정확도와 반응시간 모두에서 일반아동보다 유의미하게 저조한 수행을 보였 다. 논의 및 결론: 읽기이해부진아동은 일반아동에 비하여 음운 및 의미적으로 관련된 부적절한 정보에 대한 억제능력이 저조함을 알 수 있었다. 읽기이해부진아동의 이러한 결함은 읽기이해에 있어서 단어와 관련된 부적절한 음운 및 의미정보의 억제가 비효율적일 것 이라 예상할 수 있다.

핵심어: 읽기이해부진아동, 단어재인, 단어처리, 어휘지식, 단어유추, 억제결함

\section{참고문헌}

고선희, 최경순, 황민아(2010). 읽기이해부진아동의 다의어 의미 처리 특성. 언어청각장애연구, 15, 348-356.

고영민(2006). 단순언어장애 아동의 언어유추추론능력. 단국대학교 대학원 석사학위논문.

곽금주, 박혜원, 김청택(2001). 한국판아동용웩슬러지능검사(K-WISC-III). 서울: 도서출판특수교육.

김광해(2003). 등급별 국어교육용 어휘. 서울: 도서출판 박이정.

김애화, 황민아(2008). 초등학교 고학년의 읽기능력에 영향을 미치는 읽기관련 변인에 관한 연구. 언어청각장애연구, 13, 1-25.

박경숙, 김계옥, 송영준, 정동영, 정인숙(2008). 기초학력검사(KISE-BAAT). 아산: 국립특수교육원.

정미란(2009a). 초등학교 3-6학년 읽기이해 부진학생의 읽기이해력 예측 변인 탐색. 단국대학교 대학원 박사학위논문.

정미란(2009b). 초등학교 3-6학년 읽기이해 부진학생의 단어 유추. 언어청각장애연구, 14, 275-287.

조명한, 이정모, 김정오, 신현정, 이광오, 도경수, 이양, 이현진, 김영진, 김소영, 고성룡, 정혜선(2003). 언어심리학. 서울: 학지사.

최경순, 황민아(2010). 읽기이해부진아동의 의미 처리 특성: 의미점화효과. 언어청각장애연구, $15,168-176$.

황민아, 최경순(2011). 읽기이해부진아동의 어휘판단에서 단어길이 효과. 언어청각장애연구, 16, 570-581. 